\title{
Long non-coding RNA regulation of TRAIL in breast cancer: A tangle of non-coding threads (Review)
}

\author{
ZEESHAN JAVED ${ }^{1 *}$, KHUSHBUKHAT KHAN ${ }^{2 *}$, MUHAMMAD ZAHEER IQBAL $^{3}$, TOUQEER AHMAD ${ }^{4}$, \\ QAMAR RAZA $^{5}$, HALEEMA SADIA $^{6}$, SHAHID RAZA $^{1}$, BAHARE SALEHI $^{7,8}$, \\ JAVAD SHARIFI-RAD ${ }^{9}$ and WILLIAM C. $\mathrm{CHO}^{10}$
}

\author{
${ }^{1}$ Office for Research Innovation and Commercialization, Lahore Garrison University, Lahore, Punjab 54792; \\ ${ }^{2}$ Atta-ur-Rahman School of Applied Biosciences, National University of Sciences and Technology, Islamabad, Punjab 44000; \\ ${ }^{3}$ Center for Excellence in Molecular Biology, University of the Punjab, Lahore, Punjab 53700; ${ }^{4}$ Institute of Microbiology; \\ ${ }^{5}$ Institute of Biochemistry and Biotechnology, University of Veterinary and Animal Sciences, Lahore, Punjab 54000; \\ ${ }^{6}$ Department of Biotechnology, Balochistan University of Information Technology, Engineering and Management Sciences, \\ Quetta, Balochistan 87100, Pakistan; ${ }^{7}$ Noncommunicable Diseases Research Center, Bam University of Medical Sciences, \\ Bam 44340847; ${ }^{8}$ Student Research Committee, School of Medicine, Bam University of Medical Sciences, Bam 44340847; \\ ${ }^{9}$ Phytochemistry Research Center, Shahid Beheshti University of Medical Sciences, \\ Tehran 1991953381, Iran; ${ }^{10}$ Department of Clinical Oncology, \\ Queen Elizabeth Hospital, Hong Kong SAR, P.R. China
}

Received January 2, 2020; Accepted May 5, 2020

DOI: $10.3892 / \mathrm{ol} .2020 .11896$

\begin{abstract}
Breast cancer is a complex disease posing a serious threat to the female population worldwide. A complex molecular landscape and tumor heterogeneity render breast cancer cells resistant to drugs and able to promote metastasis and invasiveness. Despite the recent advancements in diagnostics and drug discovery, finding an effective cure for breast cancer is still a major challenge. Positive and negative regulation of apoptosis has been a subject of extensive study over the years. Numerous studies have shed light on the mechanisms that impede the tumor necrosis factor-related apoptosis-inducing ligand (TRAIL) signaling cascade. Long non-coding RNAs (lncRNAs) have been implicated in the orchestration, development, proliferation, differentiation and metastasis of breast cancer. However, the roles of lncRNAs in fine-tuning apoptosis regulating machinery in breast cancer remain to be elucidated.
\end{abstract}

The present review illuminates the roles of these molecules in the regulation of breast cancer and the interplay between lncRNA and TRAIL in breast cancer. The present review also attempts to reveal their role in the regulation of apoptosis in breast cancer appears a promising approach for the development of new diagnostic and therapeutic regimens.

\section{Contents}

1. Introduction

2. Role of IncRNA in breast cancer

3. Interplay of IncRNA and TRAIL in breast cancer

4. Conclusion

\section{Introduction}

In recent years, there has been an upsurge in cancer burden worldwide, and cancer has become the leading cause of death, following cardiovascular diseases, in both men and women globally (1). There are nearly 18 million cases of cancer registered worldwide; among them, 268,600 are breast cancer patients (2). Among the different cancer types, breast cancer is one of the major causes of death in the female population (3). Compelling evidence suggests that specific genetic, epigenetic and environmental factors play a critical role in the development of breast cancer. The prevalence of breast cancer is caused by many factors, including unhealthy lifestyle, excessive consumption of red meat, alcohol, smoking and genetics (4). Nowadays, high-throughput technologies, such as next-generation sequencing have begun to elucidate tumor 
heterogeneity and has brought us closer towards devising new diagnostic and therapeutic strategies (5). Advanced experimental methodologies have started to categorize proteome into sub-classes of pro-apoptotic and anti-apoptotic proteins (5). This has led to characterization of tumor necrosis factor (TNF)-related apoptosis-inducing ligand (TRAIL) sub-proteomes (5). Alterations in the TRAIL-mediated signaling pathway are associated with the proliferation of breast cancer (6). Translation and functional studies have clarified the underlying mechanisms and biomolecular signatures responsible for impeding cancer treatment $(7,8)$ Thus, the search for better diagnostic and management of breast cancer is needed.

Positive and negative regulation of apoptosis has been a subject of extensive study over the past decades (9). There has been an increase in new regulators of apoptosis that have deepened our understanding of the process (10). A number of studies have investigated the mechanisms that impede the TRAIL signaling cascade (11-13). Knowledge of the association between different pro-survival and cell death pathways in cancer is vital for devising therapeutic strategies for cancer. TRAIL belongs to a small subset of pro-apoptotic protein ligands in the TNF superfamily, which also includes TNF and cluster of differentiation (CD)95L (FasL/APO-1L) (14). TRAIL has been investigated since 1997, when it was observed that TRAIL-mediated apoptosis was responsible for death in cancer cells, leaving normal cells intact (15). This was followed by a number of studies documenting the molecular characteristics of TRAIL-mediated apoptosis in various cancer types, such as breast (16), thyroid (17), colorectal (18), renal (19), bladder, prostate (20) and ovarian cancer (21). Parallel studies revealed that in cancer cells, TRAIL was underexpressed, leading to loss of TRAIL-induced apoptosis (22-24). TRAIL-induced apoptosis is triggered through the activation of death receptors (DRs), specifically DR4 and DR5 (25). This interaction in turn facilitates the attachment of the apoptosis antigen 1 (Fas)-associated death domain containing protein (FADD) (26). FADD attachment results in the recruitment of adapter proteins to the cytoplasmic domain of DR (26). Recruitment of adapter proteins facilitates the activation of pro-caspases 8 and 10, which then trigger the activation of caspase 3 (27). Activation of caspase 3 in turn leads to activation of either the extrinsic pathway (caspase 8-mediated) or the intrinsic pathway, which involves the release of cytochrome $c$ (28). Cytochrome $c$-mediated activation of procaspase 9 to caspase 9 promotes activation of the intrinsic pathway, which involves the translocation of the $\mathrm{BH} 3$ interacting-domain death agonist to the mitochondria (29). This facilitates recruitment of Bax/Bak, which aid in the transportation of cytochrome $c$ and second mitochondria-derived activator of caspases/Diablo homolog through the formation of the mitochondrial pore $(30,31)$.

Long non-coding RNAs (lncRNAs) are RNA molecules in the range of 200-2,000 bp (32). IncRNAs have been found to play a crucial role in the development of various cancer types, including breast (33), thyroid (34), renal (35), colorectal (36), prostate (37) and ovarian cancer (38), and have been reported to interact with various molecules during transcription, chromosome remodeling, cellular trafficking and translation (39). In addition, lncRNAs serve regulatory roles during transcription,
mRNA processing, maturation of mRNAs, modification of histone complexes and DNA methyltransferase modifications that occur during epigenetic regulation (Fig. 1) (40). Mutations in the signaling cascades responsible for growth arrest and apoptosis are predominant in most breast cancers. lncRNA-mediated regulation of apoptosis machinery in breast cancer remains to be elucidated. Nevertheless, various studies have reported the regulatory role of IncRNAs in apoptosis and growth arrest $(41,42)$. Exploring the role of lncRNA in the regulation of the apoptosis and growth arrest in breast cancer appears a promising approach, which may aid in the development of IncRNA-based therapeutics, as well as being a biomarker for disease diagnosis.

\section{Role of IncRNA in breast cancer}

Bioinformatics studies and RNA sequencing have been used to delineate the role of lncRNA in breast cancer (43). Genetic heterogeneity of the individual tumor is a crucial factor that triggers activation of certain lncRNAs (44).

$\mathrm{X}$ inactive specific transcript (XIST) is an oncogenic lncRNA that plays a significant role in the progression of breast cancer. XIST RNA directs transcriptional changes by binding to poly comb repressive complex 2 (PRC2). Deregulated XIST promotes tumor progression (45). XIST activation has been reported to accelerate tumor growth of breast cancer gene 1-deficient ovarian cell lines (46). Accumulation of XIST promotes the expression of X-linked oncogenes, including the V-RAF murine sarcoma 3611 oncogene homolog 1 and member of ETS oncogene family, which triggers the growth of tumor cells (47). Several factors are prerequisite for triggering XIST. A recent study has reported that scaffold attachment factor A, also known as heterogenous ribonucleoprotein U, aids lncRNA attachment to the $\mathrm{X}$ chromosome. This promotes activation of SMART/histone deacetylase (HDAC)1-associated repressor protein, which recruits HDAC C3 and PRC2 components to formulate histone repressive complex (48). In addition, high-throughput sequencing has revealed that several XIST interactors serve a role in the activation of XIST. In a recent study, lower expression of XIST was reported in triple-negative breast cancer (TNBC). The restored expression of XIST reduces the epithelial-mesenchymal transition (EMT) property of cancer cells and cell proliferation, and induces apoptosis (49). XIST in TNBC functions by inhibiting microRNA (miR)-454 (49). XIST expression is also reported to be downregulated in estrogen receptor-negative $\left(\mathrm{ER}^{-}\right)$ and progesterone receptor-negative ( $\left.\mathrm{PR}^{-}\right)$breast cancer $(50)$. However, XIST is highly expressed in human epidermal growth factor receptor 2 (HER2)-positive breast cancer (51).

HOX antisense intergenic RNA (HOTAIR) is another IncRNA that has been reported to facilitate cancer progression (52). Despite its location at chromosome 12, HOTAIR has been reported to activate distant genes. Functional studies have shed light on the important role of HOTAIR in metastasis and invasion. Hepatocyte nuclear factor $4-\alpha(\mathrm{HNF} 4-\alpha)$, an initiator of epithelial differentiation, represses the transcription of HOTAIR (53). HNF4- $\alpha$ promotes the release of the chromatin loop on the HOTAIR regulatory element and a decrease in the expression levels of homeobox D cluster-targeted genes (54). PRC2 and lysine-specific demethylase 1 (LSD1) are the 

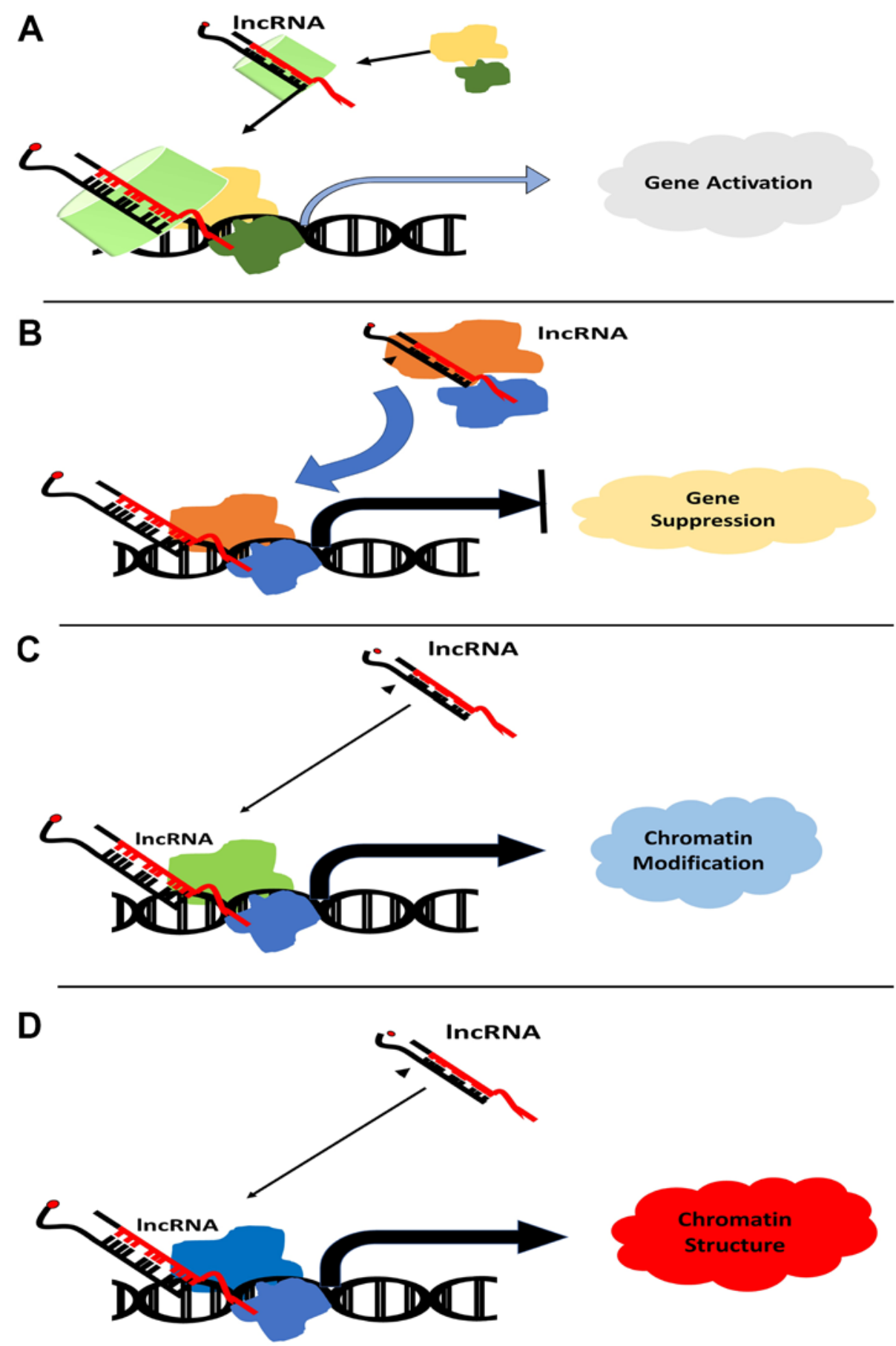

Figure 1. IncRNA-based modulation of gene expression via epigenetic modification. IncRNA can induce (A) gene activation or (B) suppression by inducing histone demethylation and histone methylation, respectively. Histone modification further allows recruitment of transcription factors or transcription repressor to the promoter region according to the fate of the gene. (C) and (D) lncRNAs also induce chromatin modification for silencing or promoting expression of gene. lncRNA, long non-coding RNA.

two regulators of chromatin dynamics that interact with HOTAIR (55). HOTAIR interacts with either LSD1 or PRC2 via various mechanisms; its interaction with PRC2 is through its 5' end, which enhances repression of PRC2 target loci (56). By contrast, HOTAIR interacts with LSD1 through its $3^{\prime}$ end to regulate gene silencing (57). HOTAIR is highly overexpressed in various cancer types, such as hepatocellular carcinoma (58), lung (59) and breast cancer (60) and has been reported to serve a decisive role in tumor proliferation, invasion and metastasis (61). Thus, HOTAIR could be considered as a plasma based biomarker for breast cancer and various tumors. Furthermore, the consistent overexpression of HOTAIR is observed in $\mathrm{ER}^{+} / \mathrm{PR}^{+}$breast cancer (62). Overexpression of HOTAIR increases invasiveness in metastatic breast cancer (63). This has led to the conclusion that HOTAIR is a valid biomarker for breast cancer (64).

NEAT1 is an oncogenic lncRNA that promotes proliferation and metastasis in breast cancer (65). NEAT1 lncRNA is highly expressed in breast cancer tissues, and its expression correlates with tumor size and metastatic potential. NEAT1 
interacts with the FOXN3, SIN3 and SIN3A repressor complex. This has been brought to light by RNA immunoprecipitation and high-throughput sequencing. Together, this trio forms a nucleoprotein complex that facilitates EMT, invasion and metastasis in $\mathrm{ER}^{+}$cells via inhibition of GATA binding protein 3 (GATA3), a transcription factor (66). In addition, overexpression of $N E A T 1$ and FOXN3 decreases overall survival rate in breast cancer patients (66). Elevated NEATI expression has also been reported in TNBC, and its inhibition via short hairpin (sh)NEAT1 in TNBC cells leads to sensitization to chemotherapy and reduced cancer stemness (67). NEATI overexpression is directly associated with enhanced tumor growth, proliferation and metastasis $(68,69)$. Tests, including MTT and wound healing assays, on BC MDA-MB-468 and MCF-7 cell lines revealed that the suppression of NEATI expression via small interfering (si)RNA, not only reduces cell proliferation and inhibits metastasis, but also prompts apoptosis via the activation of caspase 3 (65). The expression of NEAT1 is modulated by miR-548ar. Overexpression of miR-548ar significantly reduced NEATI expression levels in MCF-7 and MDA-MB-231 human breast cell lines and also facilitated the induction of cellular apoptosis (70). The role NEAT1 plays in breast cancer proliferation, invasiveness and chemo-resistance makes it a potential diagnostic biomarker and a therapeutic target for this cancer (69).

$B C A R 4$ is another IncRNA that has been demonstrated to confer tamoxifen resistance independently of ER1 expression (71). Ectopic expression of BCAR4 in MCF7 and ZR-75-1 cell lines was able to increase proliferation in estrogen-free media (72). Furthermore, BCAR4 overexpression was shown to promote growth and metastasis in primary breast tumor cells. In xenograft models, $B C A R 4$ is a potent proliferative agent; its expression is tissue-specific, thus making it a suitable target for treating anti-estrogen resistance in breast cancer (72). $B C A R 4$ promotes the expression of GLI-2 via activation of the non-canonical hedgehog-Gli pathway (73). This activation, in turn, promotes metastasis, migration and invasiveness. BCAR4 also promotes the activation of phosphatase 1 (PP1) via Smad nuclear interacting protein 1 (SNIP1), thus inhibiting p300-mediated histone acetylation (74). PP1 interaction with SNIP1 also promotes the dephosphorylation of pol II ser5, which promotes activation of GLI2 target genes (75).

$D S C A M-A S 1$ is another oncogenic IncRNA whose expression is regulated by ER (76). DSCAM-ASl has been reported as a downstream effector of ER and its upregulation has been observed in $\mathrm{ER}^{+}$and $\mathrm{ER}^{-}$breast tumors (76). Strong estrogen induction in MCF7 and T47D cells can promote overexpression of DSCAM-AS1 (77). Knockdown of DSCAM-ASI results in growth arrest and decreased migration and invasiveness, suggesting that $D S C A M-A S 1$ functions downstream of ER (76). These findings shed light on the use of DSCAM-ASI as a potential biomarker for the detection of breast cancer.

Few studies have been performed to indicate breast cancer subtype-specific expression of lncRNAs (78); however, the underlying mechanism for the tumorigenicity in breast cancer remains to be elucidated.

IncRNA in metastatic breast cancer. The contribution of IncRNAs to the growth, proliferation and survival of different types of cancer has been studied $(36,46,79-83)$ Several studies have emphasized the potential of lncRNAs in promoting metastasis in breast cancer cell lines and tissues $(84,85)$. Dysregulation of IncRNA inhibiting proliferation and metastasis (NLIPMT) has been reported to enhance growth and metastasis in breast cancer tissue. Restoration of NLIPMT expression in the breast cancer MDA-MB-231 cell line inhibits cellular proliferation by suppressing glycogen synthase kinase $3 \beta$ phosphorylation (86). Some lncRNAs are overexpressed in breast cancer cells, which facilitates tumor growth, spread and survival by targeting the transcription of proteins. Such lncRNAs are associated with cell growth suppression and apoptosis (87). High expression of lncRNA FOXD3-AS1 in cancer tissues has a direct correlation with tumor size increase and distant metastasis (88). A high level of lncRNA $A W P P H$ in patients' plasma is associated with enhanced cell growth in early stage TNBC (89). Overexpression of lncRNA $A W P P H$ causes resistance to carboplatin treatment (89).

Dysregulation of some lncRNAs is also associated with the potential of breast tumor cells to metastasize to different organ sites (90). The majority of studies have reported an IncRNA role in the metastasis of breast cancer to the lungs $(91,92)$. LINC00478-associated cytoplasmic RNA (lacRNA) is a cleaved version of IncRNA LINC00478. LINC00478 is significantly downregulated in metastatic breast tumors and promotes active transcription of $M Y C$ proto-oncogene (MYC)-activated genes (93). IncRNA overexpression suppresses the metastatic and invasive potential of breast cancer cells by stabilizing prohibitin-2 (PHB2) protein. PHB2 then brings about transcriptional inhibition of MYC target genes (93). Furthermore, its overexpression inhibits lung metastasis in mouse models (93). lncRNA HOXA11-AS is also reported to be associated with breast cancer metastasis to the lungs; it modulates EMT by downregulating E-cadherin and vimentin expression. In mouse models treated with shHOXA11-AS, the expression of HOXA11-AS is decreased in both primary and secondary tumors (94). IncRNA $A N C R$ is downregulated in breast tumor cells and induces metastasis via active signal transduction through the TGF- $\beta$ pathway (95). Upon introduction of $A N C R$-deficient MDA-MB-231-ANCR cells into BABL/c nude mice, these cells metastasize to the lungs (95).

The role of lncRNAs in promoting metastasis in breast cancer subtypes with different molecular signatures, such as luminal A, luminal B, HER2-type, normal-like and triple-negative, has yet to be properly studied. This indicates the need for further studies in the area to better understand the role of lncRNAs in breast cancer according to the different subtypes. This may be helpful in designing more effective therapeutics for this disease.

\section{Interplay of IncRNA and TRAIL in breast cancer}

lncRNAs have a dual role in cellular homeostasis. Depending on their interactive molecular landscape they can either favor survival of the cancer cells or apoptosis (84). TRAIL-mediated apoptosis is one such pathway and the alteration in the expression of its members shifts the balance of the cell in favor of survival $(96,97)$. Recent advances in biomolecular studies have hinted towards the association of the interplay of TRAIL and lncRNA with breast cancer development (77). The activity of caspases is a chief factor that is modulated by most lncRNAs in 
Table I. IncRNAs whose expression modulates caspase activity.

\begin{tabular}{|c|c|c|c|c|}
\hline Author, year & lncRNA & Affected caspase & lncRNA role & (Refs.) \\
\hline Yang et al, 2019 & POU3F3 & Caspase 9 & Enhances proteolytic activation & (99) \\
\hline Zhang et al, 2019 & NEAT1 & Caspase 3 & Inhibits activity & $(65)$ \\
\hline Gooding et al, 2017 & $B O R G$ & Caspase $3,7,8$ & Inhibits activity & $(107)$ \\
\hline Wang et al, 2018 & $Z 38$ & Caspase 3,9 & Inhibits activity & $(110)$ \\
\hline Li et al, 2017 & $T U G 1$ & Caspase 3, 9 & Inhibits activity & $(98)$ \\
\hline Ma et al, 2019 & $A F A P 1-A S 1$ & Caspase 3 & Inhibits activity & $(113)$ \\
\hline
\end{tabular}

lncRNAs, long non-coding RNAs.

breast cancer to ensure the rapid multiplication and growth of cancerous cells (98). Table I contains a list of lncRNAs whose dysregulation in breast cancer disrupts the TRAIL-induced apoptosis pathway by modulating the activity of caspases. The modulatory role of lncRNA in the extrinsic pathway is illustrated in Fig. 2.

IncRNA-mediated regulation of the extrinsic apoptotic pathway in breast cancer. POU $3 F 3$ lncRNA modulates the TRAIL pathway by modulating caspase activation (99). Data have suggested a positive correlation between tumor proliferation in TNBC and POU3F3 (99). POU3F3 inhibits the proteolytic cleavage-mediated activation of caspase 9 (99). High $P O U 3 F 3$ expression in tumor tissues and in the blood plasma of patients suggests its use as a diagnostic marker for TNBC (99).

In addition, in vitro knockdown of POU3F3 leads to enhanced cleavage of caspase 9, restoring the intrinsic apoptotic pathway, triggering growth arrest, and inhibiting tumor migration and invasiveness (100). A previous study showed that exogenous induction of procaspase 9 cleavage brings about attenuation in the oncogenic effects of overexpressed $P O U 3 F 3$ and leads to cell apoptosis (99). These findings suggest that $P O U 3 F 3$ as a potential therapeutic target for TNBC.

The extrinsic and intrinsic apoptotic pathways are both regulated by the various lncRNAs (101). Death receptor triggers the activation of caspases. Several lncRNAs serve pivotal roles in the regulation of caspase activity (101). HOXASI/2 is involved in inhibition of caspase 8 and 3 (102). NEATl inhibits the activity of caspase 3 (65) and $T U G$ promotes the activity of caspase 8 . Signals from caspases are transferred to mitochondria and lead to apoptosis. IncRNAs such as GAS5/AFAP1-AS and $M A G 12-A S 3$ promote the upregulation of $B C L-2$ and $F A S$ genes and facilitate apoptosis (103-105). IncRNA PANDA (p21-associated ncRNA DNA damage activated) downregulates the expression of proapoptotic proteins such as the Fas cell surface death receptor (FAS)/BCL-2 interacting killer (BIK) and apoptotic protease activating factor (APAF)1, thus inhibiting apoptosis and promoting cell growth in breast cancer cells (106).

$B O R G$ (BMP/OP Responsive Gene) is another highly expressed oncogenic lncRNA in breast cancer that affects caspases activity in order stop the apoptotic pathway of cells and promote aggressive tumor proliferation (107). High expression of $B O R G$ has been reported in TNBC and is also associated with chemoresistance and high cancer cell growth (108). The activity of caspase 3,7 and 8 significantly reduces the expression of BORG in BORG-expressing cell lines (107).

Suppression subtractive hybridization in combination with reverse dot-blotting suggests the correlation between high expression of lncRNA Z38 and tumorigenesis in breast cancer cells. Suppression of Z38 expression via shRNA causes inhibition of in vivo tumorigenesis and a reduction in cell viability. In addition, the TUNEL assay performed after administration of $Z 38$ siRNA reveals induction of apoptosis in cancerous cells (109). This study indicated that the administration of $Z 38$ siRNA mechanistically activates the intrinsic apoptotic pathway. Knockdown of Z38 negatively influences cell proliferative rate together with the induction of apoptosis in gastric cancer in a similar way in breast cancer (109). Z38 acts through the activation of caspase 3 and 9 to initiate the apoptotic pathway (110). High expression of Z38 and its oncogenic influence makes it prognostically significant in cases of breast cancer (111).

$A F A P 1-A S 1$ is also among the lncRNAs whose aberrant expression in breast cancer leads to the inactivity of various caspases. AFAP-AS1 is mapped on chromosome 4 in humans and its transcription occurs in an anti-sense direction from the AFAPl gene (112). Reverse transcription-quantitative PCR (RT-qPCR) confirms that $A F A P 1-A S 1$ overexpression is observed in breast cancer tissues and MCF-7, SK-BR3, MDA-MB-231 and MDA-MB-436 breast cancer cell lines. Caspase 3 activity assay, cell cycle analysis, and Bax and Bcl-2 expression analyses demonstrate that the rate of apoptosis is increased in AFAPI-AS1 siRNA-transfected cell lines due to the restored activity of caspase 3 and increased Bcl-2 expression (113).

The malignant role of lncRNA TUG1 is controversial. However, recent data has reported the association of TUG1 high expression with malignancy and increased invasiveness in breast cancer (98). TUGl overexpression is observed in malignant breast cancer cell lines such as MDA-MB-231, MDA-MB-436, MCF7 and T47D. TUG1 overexpression is reported at the highest levels in the breast cancer highly invasive MDA-MB-231 and MDA-MB-436 cell lines (98). TUG1 promotes cell proliferation by inhibiting caspase 3 and caspase 9 activities. The knockdown of TUG1 results in augmented activity of both caspases, which leads to a reduction in metastasis and increased apoptosis (98). Conversely, TUG1 


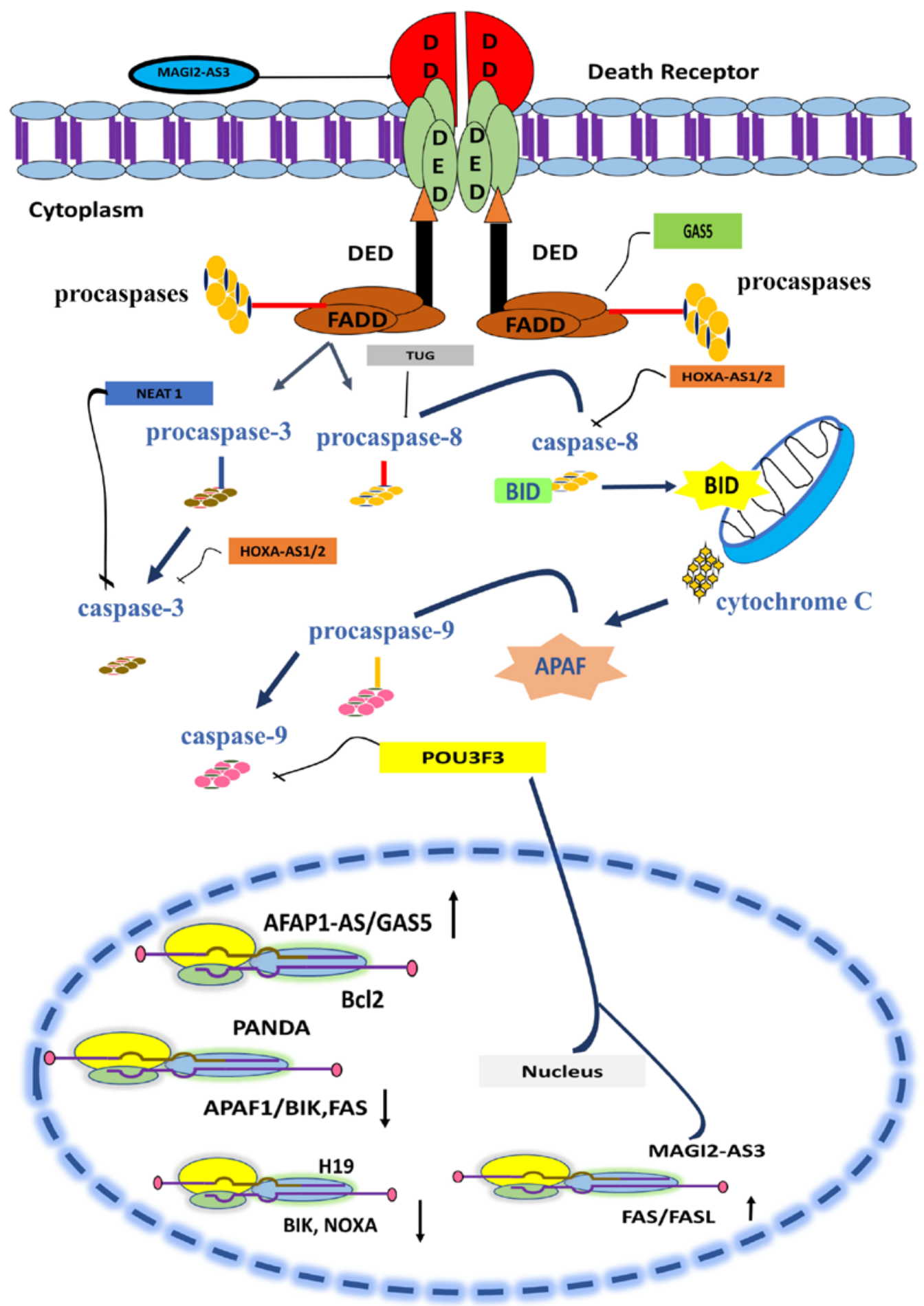

Figure 2. Schematic description of TRAIL signaling cascade and interaction of lncRNA. IncRNAs modulate the apoptotic pathway at different levels. A few lncRNAs promote apoptosis; for instance, MAGI2-AS3 enhances Fas ligand expression and APAF1-AS/GAS5 upregulates Bcl-2 expression. A few lncRNAs halt apoptosis and promote cell survival and growth; PANDA downregulates pro-apoptotic BIK protein, APAF-1 and Fas expression, and H19 downregulates BIK expression. NEAT-1 and HOXA-AS1/2 inhibit caspase 3 activity, while POU3F3 causes inhibition of caspase 9. HOXA-AS1/2 and TUG suppress activation of caspase 8. TRAIL, tumor necrosis factor-related apoptosis-inducing ligand; lncRNA, long non-coding RNA; BIK, Bcl2 interacting killer; APAF, apoptotic protease-activating factor-1; Fas, apoptosis antigen 1.

expression induced in MDA-MB-231 and MCF7 by transfecting them with pCDNA-TUG suggests that the overexpression of TUG1 has tumor-suppressive effect on cancer cells where it modulates cell growth by suppressing the expression of cyclin D1 and CDK4, and promotes cell apoptosis and retards cancer cell growth (114). The tumor-suppressive role of TUG1 is also demonstrated in TNBC. A recent study has reported that lower expression of TUG1 induces chemo-therapy resistance and promotes cell proliferation, but whether its high expression activates TRAIL-induced apoptosis is not demonstrated (115).

Cancer cells manage to grow and survive after hijacking TRAIL-mediated apoptosis (116). Tumor cells use Fas 
Table II. TRAIL-specific lncRNAs involved in breast cancer and their targets.

\begin{tabular}{|c|c|c|c|c|c|}
\hline Author, year & $\operatorname{lncRNA}$ & Expression & Target & Mechanism & (Refs.) \\
\hline Si et al, 2016 & $H 19$ & High & BIK & Blocking promoter region & (121) \\
\hline $\begin{array}{l}\text { Hung et al, 2011, } \\
\text { Zhang et al, } 2014\end{array}$ & PANDA & High & $\begin{array}{l}\text { APAF1, BIK, } \\
\text { FAS }\end{array}$ & Interact with NF-YA & $(127,128)$ \\
\hline He et al, 2015 & $G A S-5$ & Low & BIK & $\begin{array}{l}\text { Expression activation via } \\
\text { epigenetic modification }\end{array}$ & (133) \\
\hline Zhang et al, 2019 & CASC-2 & Low & Smad-2 & Direct inhibition & (137) \\
\hline Si et al, 2016 & HOXA-AS2 & High & TGFBR2 & $\begin{array}{l}\text { Expression facilitation via directly } \\
\text { inhibiting miR-520c-3p }\end{array}$ & (121) \\
\hline
\end{tabular}

BIK, Bcl2 interacting killer; APAF, apoptotic protease-activating factor-1; CASC-2, cancer susceptibility 2; FAS, apoptosis antigen 1; GAS, growth arrest-specific 5; HOXA-AS2, HOXA cluster antisense 2 RNA; NF-YA, nuclear transcription factor Y; PANDA, p21-associated ncRNA DNA damage activated; TGFBR2, tumor growth factor $\beta$ receptor 2.

receptor as a reserve route to initiate activation of caspase 8 via proteolytic cleavage and hence induce apoptosis $(117,118)$. In breast cancer, the expression levels of Fas and FasL are also downregulated, eliminating all apoptotic threats for cancerous cells and making their proliferation possible (119). In breast cancer tissue, the expression of Fas and FasL is reported to be positively correlated with the expression of lncRNA MAGI2-AS3 (105). Using transcript transfection and lentiviral approaches, Yang et al (120) reported that MAGI2-AS3 expression facilitates the upregulation of Fas and FasL expression in MDA-MB-231 and MCF-7 cell lines. CCK-8 assay and flow cytometry further demonstrated that the lentivirus-induced expression of MAGI2-AS3 reduces cell viability and promotes cell death via activation of the Fas/FasL-induced apoptotic pathway (120).

IncRNA-mediated regulation of the intrinsic apoptotic pathway in breast cancer. A few identified lncRNAs negatively modulate the TRAIL-induced apoptotic pathway by affecting the transcription of pro-apoptotic proteins whose expression is triggered by TRAIL signaling (Table II). Among them; overexpression of $\mathrm{H} 19$ is reported in $\mathrm{ER} \alpha^{+}$breast cancer cells, where it halts apoptotic signaling of the cell by suppressing transcription of BIK and NOXA genes (121). Due to its aberrant levels in $\mathrm{ER} \alpha^{+}$breast cancer tissues and patients' plasma, it has the potential to be used as a diagnostic marker for this breast cancer type (122-124). IncRNA H19, with the help of epigenetic modification, brings about the silencing of the $B I K$ gene; it blocks the promoter region of $B I K$ by facilitating the recruitment of EZH2, which then induces trimethylation of histone $\mathrm{H} 3$ at lysine 27 (121). A recent development has revealed that the expression of IncRNA H19 is modulated by lncRNA PTCSC3 in TNBC (77). The high H19 level in TNBC tumor tissues is inversely correlated with PTCSC3 expression. Wang et al $(121,122)$ transfected the BT-549 and HCC70 cell lines with PTCSC 3 vectors and reported that overexpression of PTCSC3 attenuates the expression of lncRNA $H 19$ and consequently suppresses cancer cell proliferation. Considering the role of IncRNA H19 in the rapid proliferation and chemo-resistance of breast cancer (125), treatment with
PTCSC 3 could be a potential strategy to counter the oncogenic effects of $H 19$ in breast cancer.

lncRNA $P A N D A$ is also highly expressed in breast cancer (126). The expression of $P A N D A$ in primary breast cancer cells is induced in response to DNA damage to suppress apoptosis; its expression is reported in cells that do not contain p53 mutations, but PANDA elevated expression has no effect on p53 expression. Instead, it exerts its oncogenic influence in breast cancer cells by hindering the expression of pro-apoptotic proteins, including apoptotic protease-activating factor 1 (APAF1), BIK and FAS (126). Mechanistically, it first interacts with nuclear transcription factor NF-YA, restraining the expression of pro-apoptotic activators. Suppression of $P A N D A$ expression promotes apoptosis by upregulating the expression of $A P A F-1, F A S$ and $B I K$ gene $(127,128)$.

It has been demonstrated that the expression of lncRNA GAS5 induces apoptosis in breast cancer cells (129). Low GAS5 expression in breast cancer is associated with tumor progression and suppression of the apoptotic pathway (130). It has been found through use of IncRNA RT-PCR arrays that GAS5 expression in breast cancer is modulated by the high expression of miR-21. The exon 4 of GAS5 possesses a binding site for miR-21, and abolition of that site markedly reduces miR-21 affinity for GAS5 and also attenuates suppression of apoptosis in MDA-MB-231 cells (131). In breast cancer, miR-21 negatively regulates expression of the pro-apoptotic protein Bcl-2 (132). It is reported that the ectopic expression of GAS5 downregulates miR-21, which negatively affects the growth of tumor cells and enhances cellular death (131). More data on the tumor-suppressive capability of GAS5 have been provided by Pickard and Williams (129). The study reported that GAS5 contains HREM sequences through which it interacts with the DNA-binding domain of the glucocorticoid receptor, halting cellular growth and promoting apoptosis. The study further demonstrated that HREM oligonucleotides alone also have the capability to induce apoptosis in the absence of endogenous GAS5 expression in resistant breast cancer cells. Unfortunately, the mechanism that is triggered for inducing apoptosis upon employment of HREM sequences is not known. 
GAS5 also gives rise to the small RNA pi-sno75, which has direct correlation with enhanced TRAIL expression in breast cancer cells; it utilizes the tool of epigenetic modification to enhance the expression of TRAIL ligand. Mechanistically, pi-sno75 binds with PIWIL1/4 protein. The pair then interact with WD repeat domain 5, which brings about recruitment of human complex of proteins associated with Set 1-like complexes comprising MLL3 and UTX at the promoter region of TRAIL, which causes $\mathrm{H} 3 \mathrm{~K} 4$ methylation and $\mathrm{H} 3 \mathrm{~K} 27$ demethylation, hence facilitating activation of TRAIL transcription (133). This finding emphasizes the therapeutic significance of GAS5 and pi-sno75, the exogenous administration of which could promote apoptosis and reduce cellular viability by initiating the TRAIL-induced apoptotic pathway in breast cancer cells.

A few more involvements of lncRNA in breast cancer have been demonstrated to modulate the TRAIL-mediated apoptotic pathway by regulating downstream factors of the TGF- $\beta$ signaling pathway. It has been well established by various studies that TGF- $\beta$ induces TRAIL expression, which is necessary for preventing cancerous cell growth $(28,134)$ By contrast, the tumor-suppressive role of TGF- $\beta$ reverses in advanced types of cancer, including in breast cancer, where it promotes cancer advancement and metastasis by downregulating the expression of TRAIL (135). Long intergenic non-protein coding RNA regulator of reprograming (linc-ROR) lncRNA plays a crucial role in the upregulation of TGF- $\beta$ expression in advanced stages of cancer (136); it is highly expressed in tumor tissue and also in the highly invasive breast cancer MCF-7 and MDA-MB-231 cell lines. Knockdown of linc-ROR through siRNA in MCF-7 and MDA-MB-231 cells showed that linc-ROR silencing negatively regulates TGF- $\beta$ and the expression of its downstream factors, which consequently attenuates aggressive tumor growth (136). Unlike lncRNA linc-ROR, the expression of lncRNA CASC2 is downregulated, which facilitates TGF- $\beta$ pathway activation in advanced breast cancer (137). Induced expression of CASC2 in MCF-7 and LCC-9 cell lines via transfection with pcDNA-CASC2 results in $C A S C 2$ overexpression in these cell lines. Furthermore, $C A S C 2$ inhibits cell metastasis and promotes cell death by targeting smad-2 (a downstream factor of the TGF- $\beta$ pathway) and triggering TRAIL apoptosis (137).

TGF- $\beta$ needs to halt the apoptotic pathway in order to ensure tumor proliferation and metastasis (138). Through the application of northern blotting and qPCR, it has been determined in several mouse breast cancer cell lines, that to prompt suppression of the apoptotic pathway, TGF- $\beta$ induces the expression of a $3-\mathrm{kb}$ long transcript of lncRNA Smad7 (139). The results from TUNEL staining and RT-qPCR have established that lncRNA Smad7 functions as a downstream anti-apoptotic factor of TGF- $\beta$ signaling, the overexpression of which halts apoptosis by inhibiting Bim expression and upregulating anti-apoptotic protein differentiated embryonic chondrocyte-expressed gene 1 expression in invasive breast cancer cell lines $(139,140)$.

In TNBC, the elevated expression of IncRNA ANRIL has also been reported (141). ANRIL uses the TGF- $\beta$ signaling pathway for tumor exponential growth and suppression of the apoptotic pathway (142). CCK-8 assays in MDA-MB-231 and MDA-MB-468 cell lines have revealed that knocking down ANRIL enhances the rate of apoptosis and reduces cellular proliferation (141). RNA immunoprecipitation and luciferase reporter assays have further demonstrated that ANRIL exerts its oncogenic influence in TNBC cell lines by sponging tumor-suppressive miR-199a, which is reported to downregulate the expression of TGF- $\beta$ in TNBC (141,143-146). These findings indicate the prognostic significance of ANRIL, whose knockdown in xenografted mice not only attenuates tumor proliferation, but also promotes cell apoptosis $(94,141)$.

Elevated lncRNA HOXA-AS2 expression in tissues and cell lines of breast cancer has direct regulatory control over TGF- $\beta$ signaling via upregulation of the expression of transforming growth factor $\beta$ receptor 2 (TGFBR2), which causes tumor proliferation and invasiveness (145). HOXA-AS2 promotes TGFBR2 expression by negatively modulating expression of miR-520c-3p (146). The silencing of HOXA-AS2 causes an elevation in miR-520c-3p levels, which in turn induces suppression of TGFBR2 expression (146) The silencing of HOXA-AS2 in model mice by subcutaneously administrating siRNA-HOXA-AS2-transfected MCF-7 cells leads to a reciprocal increase in miR-520c-3p expression, which by targeting TGFBR2 induces tumor growth inhibition (146). Although this finding emphasizes that $H O X A-A S 2$ could be implemented as a therapeutic target for breast cancer, how miR-520c-3p inhibits TGF- $\beta$ signaling and activates TRAIL-mediated apoptosis currently needs to be explored.

\section{Conclusion}

Breast cancer is a highly complex disease involving a number of types and genetics. Thus, an efficient and precise therapeutic regimen for breast cancer patients can only be achieved by rapid and comprehensive prognosis and diagnosis. lncRNAs have crucial implementations in different cancer types; they have established themselves as important regulators of transcription, as well as activators of various signaling cascades. These non-coding RNA molecules are tissue-specific and have the potential to serve as biomarkers for breast cancer. However, few studies have elucidated the involvement of these micromanagers in regulating apoptosis and even fewer have addressed their interplay with TRAIL-mediated apoptosis. Technological advances in bioinformatics, sequencing and mass spectrometry have, to some extent, delineated the role of lncRNA in tumor biology. Identifying lncRNA as non-invasive biomarkers that can be robustly detected in liquid biopsies could revolutionize the way breast cancer is detected. Unearthing the many functions of ncRNAs in cancer development delves into the genomic complexity of cancer and further highlights the extensive interplay between various genetic elements in the cells.

\section{Acknowledgements}

Not applicable.

\section{Funding}

No funding was received.

\section{Availability of data and materials}

Data sharing is not applicable to this article, as no datasets were generated or analyzed during the current study. 


\section{Authors' contributions}

ZJ, KK and BS wrote the manuscript. MI, QR, TA, BS and SR revised the review. HS, JR and WC conceptualized the study and revised it critically. All authors have read and approved the manuscript.

\section{Ethics approval and consent to participate}

Not applicable.

\section{Patient consent for publication}

Not applicable.

\section{Competing interests}

The authors declare that they have no competing interests.

\section{References}

1. Torre LA, Bray F, Siegel RL, Ferlay J, Lortet-Tieulent J and Jemal A: Global cancer statistics, 2012. CA Cancer J Clin 65: 87-108, 2015.

2. Siegel RL, Miller KD and Jemal A: Cancer statistics, 2019. CA Cancer J Clin 69: 7-34, 2019.

3. DeSantis CE, Fedewa SA, Goding Sauer A, Kramer JL, Smith RA and Jemal A: Breast cancer statistics, 2015: Convergence of incidence rates between black and white women. CA Cancer J Clin 66: 31-42, 2016.

4. Zur Hausen H, Bund T and de Villiers EM: Specific nutritional infections early in life as risk factors for human colon and breast cancers several decades later. Int J Cancer 144: 1574-1583, 2019.

5. Naoum GE, Buchsbaum DJ, Tawadros F, Farooqi A and Arafat WO: Journey of TRAIL from bench to bedside and its potential role in immuno-oncology. Oncol Rev 11: 332, 2017.

6. Johnstone RW, Frew AJ and Smyth MJ: The TRAIL apoptotic pathway in cancer onset, progression and therapy. Nat Rev Cancer 8: 782-798, 2008.

7. Shi X, Li Y, Sun Y, Zhao X, Sun X, Gong T, Liang Z, Ma Y and Zhang X: Genome-wide analysis of lncRNAs, miRNAs, and mRNAs forming a prognostic scoring system in esophageal squamous cell carcinoma. PeerJ 8: e8368, 2020.

8. Tirosh I and Suvà ML: Deciphering human tumor biology by single-cell expression profiling. Ann Rev Cancer Biol 3: 151-166, 2019.

9. Farooqi AA, Mukhtar S, Riaz AM, Waseem S, Minhaj S, Dilawar BA, Malik BA, Nawaz A and Bhatti S: Wnt and SHH in prostate cancer: Trouble mongers occupy the TRAIL towards apoptosis. Cell Prolif 44: 508-515, 2011.

10. Walensky LD: Cheating death: New molecules block BAX. Trends Mol Med 25: 259-261, 2019.

11. Mazurek N, Byrd JC, Sun Y, Hafley M, Ramirez K, Burks J and Bresalier RS: Cell-surface galectin-3 confers resistance to TRAIL by impeding trafficking of death receptors in metastatic colon adenocarcinoma cells. Cell Death Differ 19: 523-533, 2012

12. Seyrek K, Richter M and Lavrik IN: Decoding the sweet regulation of apoptosis: The role of glycosylation and galectins in apoptotic signaling pathways. Cell Death Differ 26: 981-993, 2019.

13. Ivanova S, Polajnar M, Narbona-Perez AJ,Hernandez-Alvarez MI, Frager P, Slobodnyuk K, Plana N, Nebreda AR, Palacin M, Gomis RR, et al: Regulation of death receptor signaling by the autophagy protein TP53INP2. EMBO J 38: e99300, 2019.

14. Kaufmann T, Strasser A and Jost PJ: Fas death receptor signalling: Roles of Bid and XIAP. Cell Death Differ 19: 42-50, 2012.

15. Walczak H, Degli-Esposti MA, Johnson RS, Smolak PJ, Waugh JY, Boiani N, Timour MS, Gerhart MJ, Schooley KA, Smith CA, et al: TRAIL-R2: A novel apoptosis-mediating receptor for TRAIL. EMBO J 16: 5386-5397, 1997.

16. Rahman M, Davis SR, Pumphrey JG, Bao J, Nau MM, Meltzer PS and Lipkowitz S: TRAIL induces apoptosis in triple-negative breast cancer cells with a mesenchymal phenotype. Br Cancer Res Treat 113: 217-230, 2009.
17. Ahmad M and Shi Y: TRAIL-induced apoptosis of thyroid cancer cells: Potential for therapeutic intervention. Oncogene 19: 3363-3371, 2000.

18. Zhao L, Dong A, Gu J, Liu Z, Zhang Y, Zhang W, Wang Y, He L, Qian C, Qian Q and Liu X: The antitumor activity of TRAIL and IL-24 with replicating oncolytic adenovirus in colorectal cancer. Cancer Gene Ther 13: 1011-1022, 2006.

19. Brooks AD and Sayers TJ: Reduction of the antiapoptotic protein cFLIP enhances the susceptibility of human renal cancer cells to TRAIL apoptosis. Cancer Immunol Immunother 54: 499-505, 2005.

20. Voelkel-Johnson C: TRAIL-mediated signaling in prostate, bladder and renal cancer. Nat Rev Urol 8: 417-427, 2011.

21. Cuello M, Ettenberg SA, Nau MM and Lipkowitz S: Synergistic induction of apoptosis by the combination of trail and chemotherapy in chemoresistant ovarian cancer cells. Gynecol Oncol 81: 380-390, 2001

22. Finnberg NK and El-Deiry WS: TRAIL death receptors as tumor suppressors and drug targets. Cell Cycle 7: 1525-1528, 2008.

23. Zhang Y and Zhang B: TRAIL resistance of breast cancer cells is associated with constitutive endocytosis of death receptors 4 and 5. Mol Cancer Res 6: 1861-1871, 2008.

24. Tollefson AE, Toth K, Doronin K, Kuppuswamy M, Doronina OA, Lichtenstein DL, Hermiston TW, Smith CA and Wold WS: Inhibition of TRAIL-induced apoptosis and forced internalization of TRAIL receptor 1 by adenovirus proteins. J Virol 75: 8875-8887, 2001

25. Suliman A,Lam A,DattaR and Srivastava RK: Intracellular mechanisms of TRAIL: Apoptosis through mitochondrial-dependent and-independent pathways. Oncogene 20: 2122-2133, 2001

26. Screaton RA, Kiessling S, Sansom OJ, Millar CB, Maddison K, Bird A, Clarke AR and Frisch SM: Fas-associated death domain protein interacts with methyl-CpG binding domain protein 4: A potential link between genome surveillance and apoptosis. Proc Natl Acad Sci USA 100: 5211-5216, 2003.

27. Aggarwal BB, Bhardwaj U and Takada Y: Regulation of TRAIL-induced apoptosis by ectopic expression of antiapoptotic factors. In: Vitamins \& Hormones Elsevier, pp453-483, 2004

28. Jang CW, Chen $\mathrm{CH}$, Chen CC, Chen JY, Su YH and Chen RH: TGF-Beta induces apoptosis through Smad-mediated expression of DAP-kinase. Nat Cell Biol 4: 51-58, 2002.

29. Kruidering $M$ and Evan GI: Caspase- 8 in apoptosis: The beginning of 'the end'? IUBMB Life 50: 85-90, 2000.

30. Farooqi AA and De Rosa G: TRAIL and microRNAs in the treatment of prostate cancer: Therapeutic potential and role of nanotechnology. Appl Microbiol Biotechnol 97: 8849-8857, 2013.

31. Falschlehner C, Emmerich $\mathrm{CH}$, Gerlach B and Walczak $\mathrm{H}$ : TRAIL signalling: Decisions between life and death. Int J Biochem Cell Biol 39: 1462-1475, 2007.

32. Han Li C and Chen Y: Small and long non-coding RNAs: Novel targets in perspective cancer therapy. Curr Genomics 16 : 319-326, 2015

33. Müller V, Oliveira-Ferrer L, Steinbach B, Pantel K and Schwarzenbach H: Interplay of lncRNA H19/miR-675 and lncRNA NEAT1/miR-204 in breast cancer. Mol Oncol 13: 1137-1149, 2019.

34. Javed Z, Ahmed Shah F, Rajabi S, Raza Q, Iqbal Z, Ullah M, Ahmad T, Salehi B, Sharifi-Rad M, Pezzani R, et al: LncRNAs as potential therapeutic targets in thyroid cancer. Asian Pac J Cancer Prev 21: 281-287, 2020.

35. Wang A, Bao Y, Wu Z, Zhao T, Wang D, Shi J, Liu B, Sun S, Yang F, Wang $\mathrm{L}$ and $\mathrm{Qu} \mathrm{L}$ : Long noncoding RNA EGFR-AS1 promotes cell growth and metastasis via affecting HuR mediated mRNA stability of EGFR in renal cancer. Cell Death Dis 10: 154, 2019.

36. Luo $\mathrm{H}, \mathrm{Xu} \mathrm{C}$, Le W, Ge B and Wang T: lncRNA CASC11 promotes cancer cell proliferation in bladder cancer through miRNA-150. J Cell Biochem 120: 13487-13493, 2019.

37. Luo J, Wang K, Yeh S, Sun Y, Liang L, Xiao Y, Xu W, Niu Y, Cheng L, Maity SN, et al: LncRNA-p21 alters the antiandrogen enzalutamide-induced prostate cancer neuroendocrine differentiation via modulating the EZH2/STAT3 signaling. Nat Commun 10: 2571, 2019.

38. Zhang Y and Ruan F: LncRNA LEF1-AS1 promotes ovarian cancer development through interacting with miR-1285-3p. Cancer Manag Res 12: 687-694, 2020.

39. He RZ, Luo DX and Mo YY: Emerging roles of lncRNAs in the post-transcriptional regulation in cancer. Genes Dis 6: 6, 2019.

40. Lau E: Non-coding RNA: Zooming in on lncRNA functions. Nat Rev Genet 15: 574-575, 2014.

41. van Leeuwen S and Mikkers H: Long non-coding RNAs: Guardians of development. Differentiation 80: 175-183, 2010. 
42. Ye N, Wang B, Quan ZF, Cao SJ, Wen XT, Huang Y, Huang XB, Wu R, Ma XP, Yan QG, et al: Functional roles of long non-coding RNA in human breast cancer. Asian Pac J Cancer Prev 15: 5993-5997, 2014

43. Iyer MK, Niknafs YS, Malik R, Singhal U, Sahu A, Hosono Y, Barrette TR, Prensner JR, Evans JR, Zhao S, et al: The landscape of long noncoding RNAs in the human transcriptome. Nat Genet 47: 199-208, 2015.

44. Cheetham S, Gruhl F, Mattick J and Dinger M: Long noncoding RNAs and the genetics of cancer. Br J Cancer 108: 2419-2425, 2013.

45. Lee JT and Bartolomei MS: X-inactivation, imprinting, and long noncoding RNAs in health and disease. Cell 152: 1308-1323, 2013.

46. Zhang TH, Liang LZ, Liu XL, Wu JN, Su K, Chen JY and Zheng QY: LncRNA UCA1/miR-124 axis modulates TGF $\beta 1$-induced epithelial-mesenchymal transition and invasion of tongue cancer cells through JAG1/Notch signaling. J Cell Biochem 120: 10495-10504, 2019.

47. Kawakami T, Zhang C, Taniguchi T, Kim CJ, Okada Y, Sugihara H, Hattori T, Reeve AE, Ogawa O and Okamoto $\mathrm{K}$ : Characterization of loss-of-inactive $\mathrm{X}$ in Klinefelter syndrome and female-derived cancer cells. Oncogene 23: 6163-6169, 2004

48. Postlmayr A and Wutz A: Insights into the establishment of chromatin states in pluripotent cells from studies of $\mathrm{X}$ inactivation. J Mol Biol 429: 1521-1531, 2017.

49. Li X, Hou L, Yin L and Zhao S: LncRNA XIST interacts with miR-454 to inhibit cells proliferation, epithelial mesenchymal transition and induces apoptosis in triple-negative breast cancer J Biosci 45: 45, 2020.

50. Zheng R, Lin S, Guan L, Yuan H, Liu K, Liu C, Ye W, Liao Y, Jia J and Zhang R: Long non-coding RNA XIST inhibited breast cancer cell growth, migration, and invasion via miR-155/CDX 1 axis. Biochem Biophys Res Commun 498: 1002-1008, 2018.

51. Zhao L, Zhao Y, He Y, Li Q and Mao Y: The functional pathway analysis and clinical significance of miR-20a and its related IncRNAs in breast cancer. Cell Signal 51: 152-165, 2018.

52. Gupta RA, Shah N, Wang KC, Kim J, Horlings HM, Wong DJ, Tsai MC, Hung T, Argani P, Rinn JL, et al: Long non-coding RNA HOTAIR reprograms chromatin state to promote cancer metastasis. Nature 464: 1071-1076, 2010.

53. Chen $\mathrm{Y}$ and $\mathrm{Li} \mathrm{CH}$ : Novel therapeutic targets for hepatocellular carcinoma treatment. Hepatocellular Carcinoma Basic Res: 35 , 2012 doi: $10.5772 / 28894$

54. Battistelli C, Sabarese G, Santangelo L, Montaldo C, Gonzalez FJ, Tripodi $\mathrm{M}$ and Cicchini C: The IncRNA HOTAIR transcription is controlled by $\mathrm{HNF} 4 \alpha$-induced chromatin topology modulation. Cell Death Differ 26: 890-901, 2019.

55. Qu X, Alsager S, Zhuo Y and Shan B: HOX transcript antisense RNA (HOTAIR) in cancer. Cancer Lett 454: 90-97, 2019.

56. Bhan A and Mandal SS: LncRNA HOTAIR: A master regulator of chromatin dynamics and cancer. Biochim Biophys Acta 1856 $151-164,2015$.

57. Cai B, Song X, Cai J and Zhang S: HOTAIR: A cancer-related long non-coding RNA. Neoplasma 61: 379-391, 2014.

58. Yang Z, Zhou L, Wu LM, Lai MC, Xie HY, Zhang F and Zheng SS: Overexpression of long non-coding RNA HOTAIR predicts tumor recurrence in hepatocellular carcinoma patients following liver transplantation. Ann Surg Oncol 18: 1243-1250, 2011.

59. Hajjari M and Salavaty A: HOTAIR: An oncogenic long non-coding RNA in different cancers. Cancer Bio Med 12: 1-9, 2015.

60. Bhan A, Hussain I, Ansari KI, Kasiri S, Bashyal A and Mandal SS: Antisense transcript long noncoding RNA (lncRNA) HOTAIR is transcriptionally induced by estradiol. J Mol Biol 425: 3707-3722, 2013.

61. Amândio AR, Necsulea A, Joye E, Mascrez B and Duboule D Hotair is dispensible for mouse development. PLoS Genet 12: e1006232, 2016.

62. Sørensen KP, Thomassen M, Tan Q, Bak M, Cold S, Burton M, Larsen MJ and Kruse TA: Long non-coding RNA HOTAIR is an independent prognostic marker of metastasis in estrogen receptor-positive primary breast cancer. Breast cancer Res Treat 142: 529-536, 2013

63. Tao S, He H and Chen Q: Estradiol induces HOTAIR levels via GPER-mediated miR-148a inhibition in breast cancer. J Trans Med 13: 131, 2015.

64. Lv R, Zhang J, Zhang W, Huang Y, Wang N, Zhang Q and Qu S: Circulating HOTAIR expression predicts the clinical response to neoadjuvant chemotherapy in patients with breast cancer. Cancer Biomark 22: 249-256, 2018.
65. Zhang $\mathrm{M}, \mathrm{Wu} \mathrm{WB}$, Wang ZW and Wang XH: lncRNA NEAT1 is closely related with progression of breast cancer via promoting proliferation and EMT. Eur Rev Med Pharmacol Sci 21: 1020-1026, 2017

66. Li W, Zhang Z, Liu X, Cheng X, Zhang Y, Han X, Zhang Y, Liu S, Yang J, Xu B, et al: The FOXN3-NEAT1-SIN3A repressor complex promotes progression of hormonally responsive breast cancer. J Clin Invest 127: 3421-3440, 2017.

67. Shin VY, Chen J, Cheuk IW, Siu MT, Ho CW, Wang X, Jin H and Kwong A: Long non-coding RNA NEAT1 confers oncogenic role in triple-negative breast cancer through modulating chemoresistance and cancer stemness. Cell Death Dis 10: 270, 2019

68. Qian K, Liu G, Tang Z, Hu Y, Fang Y, Chen Z and Xu X: The long non-coding RNA NEAT1 interacted with miR-101 modulates breast cancer growth by targeting EZH2. Arch Biochem Biophys 615: 1-9, 2017.

69. Li X, Wang S, Li Z, Long X, Guo Z, Zhang G, Zu J, Chen Y and Wen L: The lncRNA NEAT1 facilitates cell growth and invasion via the miR-211/HMGA2 axis in breast cancer. Int J Biol Macromol 105: 346-353, 2017.

70. Ke H, Zhao L, Feng X, Xu H, Zou L, Yang Q, Su X, Peng L and Jiao B: NEAT1 is required for survival of breast cancer cells through FUS and miR-548. Gene Regul Syst Bio 10 (Suppl 1): S11-S17, 2016.

71. Godinho M, Meijer D, Setyono-Han B, Dorssers LC and van Agthoven T: Characterization of BCAR4, a novel oncogene causing endocrine resistance in human breast cancer cells. J Cell Physiol 226: 1741-1749, 2011.

72. Godinho MF, Wulfkuhle JD, Look MP, Sieuwerts AM, Sleijfer S, Foekens JA, Petricoin EF III, Dorssers LC and van Agthoven T: BCAR4 induces antioestrogen resistance but sensitises breast cancer to lapatinib. Br J Cancer 107: 947-955, 2012.

73. Xing Z, Park PK, Lin C and Yang L: LncRNA BCAR4 wires up signaling transduction in breast cancer. RNA Biol 12: 681-689, 2015.

74. Sun Q, Hao Q and Prasanth KV: Nuclear long noncoding RNAs: Key regulators of gene expression. Trends Genet 34: 142-157, 2018.

75. Godinho MF, Sieuwerts AM, Look MP, Meijer D, Foekens JA, Dorssers LC and van Agthoven T: Relevance of BCAR4 in tamoxifen resistance and tumour aggressiveness of human breast cancer. Br J Cancer 103: 1284-1291, 2010.

76. Niknafs YS, Han S, Ma T, Speers C, Zhang C, Wilder-Romans K, Iyer MK, Pitchiaya S, Malik R, Hosono Y, et al: The lncRNA landscape of breast cancer reveals a role for DSCAM-AS1 in breast cancer progression. Nat Commun 7: 12791, 2016.

77. Wang Z and Zöller M: Exosomes, metastases, and the miracle of cancer stem cell markers. Cancer Metastasis Rev 38: 259-295, 2019.

78. Ouyang D, Su J,Huang P,Li M,Li Q, Zhao P, Chen Q,Zou Q, Feng X, Qian K, et al: Identification of lncRNAs via microarray analysis for predicting HER2-negative breast cancer response to neoadjuvant chemotherapy. Int J Clin Exp Pathol 11: 2621-2628, 2018

79. Chen YK and Yen Y: The ambivalent role of lncRNA Xist in carcinogenesis. Stem Cell Rev Rep 15: 314-323, 2019.

80. Mazor G, Levin L, Picard D, Ahmadov U, Carén H, Borkhardt A, Reifenberger G, Leprivier G, Remke M and Rotblat B: The lncRNA TP73-AS1 is linked to aggressiveness in glioblastoma and promotes temozolomide resistance in glioblastoma cancer stem cells. Cell Death Dis 10: 246, 2019.

81. Wang Y, Yang L, Chen T, Liu X, Guo Y, Zhu Q, Tong X, Yang W, Xu Q, Huang D and Tu K: A novel lncRNA MCM3AP-AS1 promotes the growth of hepatocellular carcinoma by targeting miR-194-5p/FOXA1 axis. Mol Cancer 18: 28, 2019.

82. Kang CL, Qi B, Cai QQ, Fu LS, Yang Y, Tang C, Zhu P, Chen QW, Pan J, Chen MH and Wu XZ: LncRNA AY promotes hepatocellular carcinoma metastasis by stimulating ITGAV transcription. Theranostics 9: 4421-4436, 2019.

83. Zhang H, Zhu M, Du Y, Zhang H, Zhang Q, Liu Q, Huang Z, Zhang L, Li H, Xu L, et al: A panel of 12-lncRNA signature predicts survival of pancreatic adenocarcinoma. J Cancer 10 : $1550-1559,2019$

84. Yang G, Lu X and Yuan L: LncRNA: A link between RNA and cancer. Biochim Biophys Acta 1839: 1097-1109, 2014

85. Farooqi AA, Attar R, Qureshi MZ, Fayyaz S, Sohail MI, Sabitaliyevich UY, Nurmurzayevich SB, Yelekenova A, Yaylim I and Alaaeddine N: Interplay of long non-coding RNAs and TGF/SMAD signaling in different cancers. Cell Mol Biol (Noisy-le-Grand) 64: 1-6, 2018

86. Jiang Y, Lin L, Zhong S, Cai Y,Zhang F, Wang X, Miao R, Zhang B, Gao $\mathrm{S}$ and $\mathrm{Hu} \mathrm{X}$ : Overexpression of novel lncRNA NLIPMT inhibits metastasis by reducing phosphorylated glycogen synthase kinase $3 \beta$ in breast cancer. J Cell Physiol 234: 10698-10708, 2019. 
87. Liu Y, Sharma S and Watabe K: Roles of lncRNA in breast cancer. Front Biosci (Schol Ed) 7: 94-108, 2015.

88. Guan Y, Bhandari A, Xia E, Yang F, Xiang J and Wang O: lncRNA FOXD3-AS1 is associated with clinical progression and regulates cell migration and invasion in breast cancer. Cel Biochem Funct 37: 239-244, 2019.

89. Liu AN, Qu HJ, Gong WJ, Xiang JY, Yang MM and Zhang W: LncRNA AWPPH and miRNA-21 regulates cancer cell proliferation and chemosensitivity in triple-negative breast cancer by interacting with each other. J Cell Biochem 120: 14860-14866, 2019.

90. Shi SJ, Wang LJ, Yu B, Li YH, Jin Y and Bai XZ: LncRNA-ATB promotes trastuzumab resistance and invasion-metastasis cascade in breast cancer. Oncotarget 6: 11652-11663, 2015.

91. Augoff K, McCue B, Plow EF and Sossey-Alaoui K: miR-31 and its host gene lncRNA LOC554202 are regulated by promoter hypermethylation in triple-negative breast cancer. Mol Cancer 11: 5, 2012.

92.Li Z, Hou P, Fan D, Dong M, Ma M, Li H, Yao R, Li Y, Wang G, Geng P, et al: The degradation of EZH2 mediated by lncRNA ANCR attenuated the invasion and metastasis of breast cancer Cell Death Differ 24: 59-71, 2017.

93. Guo R, Su Y, Xue J, Si J, Chi Y and Wu J: Abstract P6-05-01 A novel cleaved cytoplasmic lncRNA LacRNA interacts with PHB2 and suppresses breast cancer metastasis via repressing MYC targets. Cancer Res: 79, 2019 doi: 10.1158/1538-7445.

94. Li W, Jia G, Qu Y, Du Q, Liu B and Liu B: Long non-coding RNA (LncRNA) HOXA11-AS promotes breast cancer invasion and metastasis by regulating epithelial-mesenchymal transition. Med Sci Monit 23: 3393-3403, 2017.

95. Li Z,Dong M,Fan D,Hou P,LiH,Liu L,Lin C,Liu J,Su L, Wu L, et al LncRNA ANCR down-regulation promotes TGF- $\beta$-induced EMT and metastasis in breast cancer. Oncotarget 8: 67329-67343, 2017.

96. Naval J, de Miguel D, Gallego-Lleyda A, Anel A and Martinez-Lostao L: Importance of TRAIL molecular anatomy in receptor oligomerization and signaling. Implications for Cancer Therapy. Cancers (Basel) 11: 444, 2019.

97. Mert U and Sanlioglu AD: Intracellular localization of DR5 and related regulatory pathways as a mechanism of resistance to TRAIL in cancer. Cell Mol Life Sci 74: 245-255, 2017.

98. Li T, Liu Y, Xiao H and Xu G: Long non-coding RNA TUG1 promotes cell proliferation and metastasis in human breast cancer. Breast Cancer 24: 535-543, 2017.

99. Yang J, Meng X, Yu Y, Pan L, Zheng Q and Lin W: LncRNA POU3F3 promotes proliferation and inhibits apoptosis of cancer cells in triple-negative breast cancer by inactivating caspase 9 . Biosci Biotechnol Biochem 83: 1117-1123, 2019.

100. Shan TD, Xu JH, Yu T, Li JY, Zhao LN, Ouyang H, Luo S, Lu XJ, Huang CZ, Lan QS, et al: Knockdown of linc-POU3F3 suppresses the proliferation, apoptosis, and migration resistance of colorectal cancer. Oncotarget 7: 961-975, 2016.

101. Rossi MN and Antonangeli F: LncRNAs: New players in apoptosis control. Int J Cell Biol 2014: 473857, 2014.

102. Qu Y, Wang Y, Wang P, Lin N, Yan X and Li Y: Overexpression of long noncoding RNA HOXA-AS2 predicts an adverse prognosis and promotes tumorigenesis via SOX4/PI3K/AKT pathway in acute myeloid leukemia. Cell Biol Int: May 5, 2020 doi: 10.1002/cbin.11370 (Epub ahead of print)

103. Awasthee N, Rai V, Verma SS, Francis KS, Nair MS and Gupta SC: Anti-cancer activities of Bharangin against breast cancer: Evidence for the role of NF- $\kappa$ B and lncRNAs. Biochim Biophys Acta Gen Subj 1862: 2738-2749, 2018.

104. Dianatpour A, Faramarzi S, Geranpayeh L, Mirfakhraie R, Motevaseli Eand Ghafouri-FardS: Expression analysis of AFAP1-AS1 and AFAP1 in breast cancer. Cancer Biomark 22: 49-54, 2018.

105. Zhang $\mathrm{H}$ and $\mathrm{Lu} \mathrm{B}$ : microRNAs as biomarkers of ovarian cancer Expert Rev Anticancer Ther 20: 373-385, 2020

106. Huang YS, Chang CC, Lee SS, Jou YS and Shih HM: Xist reduction in breast cancer upregulates AKT phosphorylation via HDAC3-mediated repression of PHLPP1 expression. Oncotarget 7: 43256, 2016

107. Gooding AJ, Zhang B, Jahanbani FK, Gilmore HL, Chang JC, Valadkhan S and Schiemann WP: The lncRNA BORG drives breast cancer metastasis and disease recurrence. Sci Rep 7: 12698, 2017.

108. Gooding AJ, Zhang B, Gunawardane L, Beard A, Valadkhan S and Schiemann WP: The IncRNA BORG facilitates the survival and chemoresistance of triple-negative breast cancers. Oncogene 38: 2020, 2019.

109. Deng R, Liu B, Wang Y, Yan F, Hu S, Wang H, Wang T, Li B, Deng X, Xiang S, Yang Y and Zhang J: High expression of the newly found long noncoding RNA Z38 promotes cell proliferation and oncogenic activity in breast cancer. J Cancer 7: 576-578, 2016.
110. Wang Y, Zheng C, Li T, Zhang R, Wang Y, Zhang J, He Q, Sun $Z$ and Wang X: Long noncoding RNA Z38 promotes cell proliferation and metastasis and inhibits cell apoptosis in human gastric cancer. Oncolo Lett 16: 6051-6058, 2018.

111. Nie ZL, Wang YS, Mei YP, Lin X, Zhang GX, Sun HL, Wang YL, Xia YX and Wang SK: Prognostic significance of long noncoding RNA Z38 as a candidate biomarker in breast cancer. J Clin Lab Anal 32: e22193, 2018.

112. Zhang F, Li J, Xiao H, Zou Y, Liu Y and Huang W: AFAP1-AS1: A novel oncogenic long non-coding RNA in human cancers. Cell Proliferation 51: e12397, 2018.

113. Ma D, Chen C, Wu J, Wang H and Wu D: Up-regulated lncRNA AFAP1-AS1 indicates a poor prognosis and promotes carcinogenesis of breast cancer. Breast Cancer 26: 74-83, 2019.

114. Fan S, Yang Z, Ke Z, Huang K, Liu N, Fang X and Wang K: Downregulation of the long non-coding RNA TUG1 is associated with cell proliferation, migration, and invasion in breast cancer. Biomed Pharmacother 95: 1636-1643, 2017.

115. Tang T, Cheng Y, She Q, Jiang Y, Chen Y, Yang W and Li Y: Long non-coding RNA TUG1 sponges miR-197 to enhance cisplatin sensitivity in triple negative breast cancer. Biomed Pharmacother 107: 338-346, 2018.

116. Ghavami S, Hashemi M, Ande SR, Yeganeh B, Xiao W, Eshraghi M, Bus CJ, Kadkhoda K, Wiechec E, Halayko AJ and Los M: Apoptosis and cancer: Mutations within caspase genes. J Med Genet 46: 497-510, 2009.

117. Rossin A, Miloro G and Hueber AO: TRAIL and FasL functions in cancer and autoimmune diseases: Towards an increasing complexity. Cancers 11: 639, 2019.

118. Eberle J: Countering TRAIL resistance in melanoma. Cancers 11: 656, 2019.

119. Kolben T, Jeschke U, Reimer T, Karsten N, Schmoeckel E, Semmlinger A, Mahner S, Harbeck N and Kolben TM: Induction of apoptosis in breast cancer cells in vitro by Fas ligand reverse signaling. J Cancer Res Clin Oncol 144: 249-256, 2018

120. Yang Y, Yang H, Xu M, Zhang H, Sun M, Mu P, Dong T, Du S and Liu K: Long non-coding RNA (IncRNA) MAGI2-AS3 inhibits breast cancer cell growth by targeting the Fas/FasL signalling pathway. Hum Cell 31: 232-241, 2018

121. Si X, Zang R, Zhang E, Liu Y, Shi X, Zhang E, Shao L, Li A, Yang N, Han X, et al: LncRNA H19 confers chemoresistance in $\mathrm{ER} \alpha$-positive breast cancer through epigenetic silencing of the pro-apoptotic gene BIK. Oncotarget 7: 81452-81462, 2016.

122. Sun H, Wang G, Peng Y,Zeng Y,Zhu QN,Li TL, Cai JQ,Zhou HH and Zhu YS: H19 lncRNA mediates 17 $\beta$-estradiol-induced cell proliferation in MCF-7 breast cancer cells. Oncol Rep 33: 3045-3052, 2015.

123. Zhang K, Luo Z, Zhang Y, Zhang L, Wu L, Liu L, Yang J, Song X and Liu J: Circulating lncRNA H19 in plasma as a novel biomarker for breast cancer. Cancer Biomark 17: 187-194, 2016.

124. Lin Y and Tao H: Diagnostic value of plasma exosomal lncRNA H19 for breast cancer. Chin J Clin Laboratory Sci 36: 99-101, 2018

125. Han J, Han B, Wu X, Hao J, Dong X, Shen Q and Pang H: Knockdown of lncRNA H19 restores chemo-sensitivity in paclitaxel-resistant triple-negative breast cancer through triggering apoptosis and regulating Akt signaling pathway. Toxicol Appl Pharmacol 359: 55-61, 2018.

126. Li J, Tian H, Yang J and Gong Z: Long noncoding RNAs regulate cell growth, proliferation, and apoptosis. DNA Cell Biol 35: $459-470,2016$

127. Hung T, Wang Y, Lin MF, Koegel AK, Kotake Y, Grant GD, Horlings HM, Shah N, Umbricht C, Wang P, et al: Extensive and coordinated transcription of noncoding RNAs within cell-cycle promoters. Nat Genet 43: 621-629, 2011.

128. Zhang A, Xu M and Mo YY: Role of the lncRNA-p53 regulatory network in cancer. J Mol Cell Biol 6: 181-191, 2014.

129. Pickard MR and Williams GT: The hormone response element mimic sequence of GAS5 lncRNA is sufficient to induce apoptosis in breast cancer cells. Oncotarget 7: 10104, 2016.

130. Zong Y, Zhang Y, Sun X, Xu T, Cheng X and Qin Y: miR-221/222 promote tumor growth and suppress apoptosis by targeting IncRNA GAS5 in breast cancer. Biosci Rep 39: BSR20181859, 2019.

131. Zhang Z, Zhu Z, Watabe K, Zhang X, Bai C, Xu M, Wu F and Mo YY: Negative regulation of lncRNA GAS5 by miR-21. Cell Death Differ 20: 1558-1568, 2013.

132. Wickramasinghe NS, Manavalan TT, Dougherty SM, Riggs KA, $\mathrm{Li} \mathrm{Y}$ and Klinge CM: Estradiol downregulates miR-21 expression and increases miR-21 target gene expression in MCF-7 breast cancer cells. Nucleic Acids Res 37: 2584-2595, 2009. 
133. He X, Chen X, Zhang X, Duan X, Pan T, Hu Q, Zhang Y, Zhong F, Liu J, Zhang H, et al: An Lnc RNA (GAS5)/SnoRNA-derived piRNA induces activation of TRAIL gene by site-specifically recruiting MLL/COMPASS-like complexes. Nucleic Acids Res 43: 3712-3725, 2015.

134. Wang Y, Chu J, Yi P, Dong W, Saultz J, Wang Y, Wang H, Scoville S, Zhang J, Wu LC, et al: SMAD4 promotes TGF- $\beta$-independent NK cell homeostasis and maturation and antitumor immunity. J Clin Invest 128: 5123-5136, 2018.

135. Cano-González A and López-Rivas A: Opposing roles of TGF- $\beta$ and EGF in the regulation of TRAIL-induced apoptosis in human breast epithelial cells. Biochim Biophys Acta 1863: 2104-2114, 2016.

136. Hou L, Tu J, Cheng F, Yang H, Yu F, Wang M, Liu J, Fan J and Zhou G: Long noncoding RNA ROR promotes breast cancer by regulating the TGF- $\beta$ pathway. Cancer Cell Int 18: 142, 2018.

137. Zhang Y, Zhu M, Sun Y, Li W, Wang Y and Yu W: Upregulation of lncRNA CASC2 suppresses cell proliferation and metastasis of breast cancer via inactivation of the TGF- $\beta$ signaling pathway. Oncol Res 27: 379-387, 2019.

138. Batlle E and Massagué J: Transforming growth factor- $\beta$ signaling in immunity and cancer. Immunity 50: 924-940, 2019.

139. Arase M, Horiguchi K, Ehata S, Morikawa M, Tsutsumi S, Aburatani H, Miyazono K and Koinuma D: Transforming growth factor- $\beta$-induced lnc RNA-Smad7 inhibits apoptosis of mouse breast cancer JygMC(A) cells. Cancer Sci 105: 974-982, 2014.

140. Hoshino Y, Katsuno Y, Ehata S and Miyazono K: Autocrine TGF- $\beta$ protects breast cancer cells from apoptosis through reduction of $\mathrm{BH} 3$-only protein, Bim. J Biochem 149: 55-65, 2011.
141. Xu ST, Xu JH, Zheng ZR, Zhao QQ, Zeng XS, Cheng SX, Liang YH and Hu QF: Long non-coding RNA ANRIL promotes carcinogenesis via sponging miR-199a in triple-negative breast cancer. Biomed Pharmacother 96: 14-21, 2017.

142. Zhao JJ, Hao S, Wang LL, Hu CY, Zhang S, Guo LJ, Zhang G, Gao B, Jiang Y, Tian WG and Luo DL: Long non-coding RNA ANRIL promotes the invasion and metastasis of thyroid cancer cells through TGF- $\beta /$ Smad signaling pathway. Oncotarget 7 : 57903-57918, 2016

143. Chen J, Shin VY, Siu MT, Ho JC, Cheuk I and Kwong A: miR-199a-5p confers tumor-suppressive role in triple-negative breast cancer. BMC Cancer 16: 887, 2016.

144. Zhang Y,Fan KJ, Sun Q, Chen AZ, Shen WL, Zhao ZH, Zheng XF and Yang X: Functional screening for miRNAs targeting Smad4 identified miR-199a as a negative regulator of TGF- $\beta$ signalling pathway. Nucleic Acids Res 40: 9286-9297, 2012.

145. Wang J, Su Z, Lu S, Fu W, Liu Z, Jiang X and Tai S: LncRNA HOXA-AS2 and its molecular mechanisms in human cancer. Clin Chim Acta 485: 229-233, 2018.

146. Fang Y, Wang J, Wu F, Song Y, Zhao S and Zhang Q: Long non-coding RNA HOXA-AS2 promotes proliferation and invasion of breast cancer by acting as a miR-520c-3p sponge. Oncotarget 8: 46090, 2017.

This work is licensed under a Creative Commons Attribution-NonCommercial-NoDerivatives 4.0 International (CC BY-NC-ND 4.0) License. 